\title{
Gradual spinal cord decompression through migration of floated plaques after anterior decompression via a posterolateral approach for OPLL in the thoracic spine
}

\author{
Satoshi Kato, MD, Hideki Murakami, MD, Satoru Demura, MD, Katsuhito Yoshioka, MD, \\ Hiroyuki Hayashi, MD, Noriaki Yokogawa, MD, Xiang Fang, MD, and Hiroyuki Tsuchiya, MD \\ Department of Orthopaedic Surgery, Kanazawa University School of Medicine, Kanazawa, Japan
}

\begin{abstract}
OBJECT Several surgical procedures have been developed to treat thoracic OPLL (ossification of the posterior longitudinal ligament). However, favorable surgical results are not always achieved, and consistent protocols and procedures for surgical treatment of OPLL in this region have not been established. Beak-type OPLL in the thoracic spine is known to be the most complicated form of OPLL to treat surgically. In this study, the authors examine the clinical outcomes after anterior decompression via a posterolateral approach for beak-type OPLL in the thoracic spine and address the gradual spinal cord decompression caused by migration of the floated plaques after surgery.
\end{abstract}

METHODS Between 2011 and 2013, a total of 12 patients with thoracic myelopathy due to OPLL were surgically treated at the authors' institute. The study group for this paper comprises 6 of those 12 patients. These 6 patients, who had beak-type OPLL, underwent with anterior decompression and instrumented fusion via the authors' posterolateral approach-based surgical technique. The other 6 patients, who exhibited other types of OPLL, underwent posterior decompression and instrumented fusion. In the study group (the 6 patients with beak-type OPLL), half of the patients (the 3 patients who were treated first) were treated with removal of the ossified ligament. These patients are referred to as the removal group. The other 3 patients were treated by means of "floating" the OPLL plaques and are referred to as the floating group. Clinical and radiographic outcomes were evaluated in these 6 cases.

RESULTS The recovery rates were $52.4 \%$ in the removal group and $60.0 \%$ in the floating group. Two patients in the removal group had operative complications, including a dural tear and temporary neurological deterioration. No operative complications were encountered in the floating group. In all 3 cases in the floating group, floating of the ossified ligament was completely achieved, and the floated plaque gradually migrated into the ventral bone resection areas. The mean migration distances of the floated plaque were $2.4 \mathrm{~mm}, 4.3 \mathrm{~mm}, 4.7 \mathrm{~mm}$, and $4.8 \mathrm{~mm}$ at $1,3,6$, and 12 months after surgery.

CONCLUSIONS Treatment of beak-type OPLL in the thoracic spine via the posterolateral approach-based floating plaque technique was safe and effective in this small case series. Gradual migration of the floated plaques provided additional spinal cord decompression during the postoperative course.

http://thejns.org/doi/abs/10.3171/2015.1.SPINE14960

KEY WORDS ossification of the posterior longitudinal ligament; thoracic spine; anterior decompression; posterolateral approach; gradual spinal cord decompression; migrating floated plaques

$\mathrm{T}$ HORACIC myelopathy consequent to ossification of the posterior longitudinal ligament (OPLL) in the thoracic spine is usually progressive and responds poorly to conservative therapy, leaving surgery as the only effective treatment option. Despite advances in surgical techniques employed for thoracic OPLL, favorable results are not always achieved. ${ }^{6}$ In patients with thoracic myelopathy resulting from OPLL in the thoracic spine, anterior decompression via removal or floating of the ossified PLL (or "plaque") is the most effective method of relieving pressure on the spinal cord..$^{1,3,5,11-13}$ However, anterior spinal cord decompression is technically demanding and has been reported to cause postoperative neurological degradation..$^{1,8}$

We developed a novel technique to remove or float the ossified PLL in the thoracic spine via a posterolateral ap-

ABBREVIATIONS JOA = Japanese Orthopaedic Association; OPLL = ossification of the PLL; PLL = posterior longitudinal ligament.

SUBMITTED September 19, 2014. ACCEPTED January 13, 2015.

INCLUDE WHEN CITING Published online July 3, 2015; DOI: 10.3171/2015.1.SPINE14960.

DISCLOSURE This work was supported by a Health Labour Sciences Research Grant. No benefits in any form have been or will be received from any commercial party related directly or indirectly to the subject of this article. 
proach. ${ }^{4}$ This procedure allows the surgeon to perform anterior decompression for the treatment of thoracic OPLL more safely and effectively than conventional procedures. This approach is especially useful for cases of beak-type OPLL, which is known to be the most complicated surgically. ${ }^{7,10}$ In our clinical cases in which the ossified PLL was floated during the procedure, we observed gradual spinal cord decompression caused by migration of the floated plaques after surgery (Figs. 1 and 2). The purpose of this study was to address this phenomenon and evaluate the clinical outcomes after anterior decompression via our procedure.

\section{Methods \\ Patient Selection}

Between 2011 and 2013, a total of 12 patients with thoracic myelopathy due to OPLL were surgically treated at our institute. Six patients with beak-type OPLL in the thoracic spine underwent anterior decompression and instrumented fusion via a posterolateral approach. The other 6 patients, who exhibited other types of OPLL, underwent posterior decompression and instrumented fusion. Among the 6 patients who underwent anterior decompression, removal of the ossified PLL was performed in the 3 patients who were treated first and floating was performed in the later 3 patients. In this study, the clinical and radiographic outcomes were primarily examined in patients who were treated with the plaque-floating technique.

\section{Clinical and Radiographic Parameters}

The surgical outcomes were assessed according to the Japanese Orthopaedic Association (JOA) score for thoracic myelopathy (total of 11 points), which was derived from the JOA scoring system for cervical myelopathy after eliminating the motor and sensory scores for the upper extremities, ${ }^{9}$ and the Hirabayashi recovery rate. ${ }^{2}$ JOA scores were recorded both before surgery and at their maximum point after surgery. The Hirabayashi recovery rate (\%) was calculated using the following formula: (postoperative JOA score - preoperative JOA score)/(11 - preoperative JOA score) $\times 100$.

The OPLL occupying ratio in the canal diameter and the migration distances of the floated plaque at $1,3,6$, and 12 months after surgery were measured using multiplanar reconstruction CT (Fig. 3). The anterior decompression ratio (\%) was defined and calculated using the following formula: (migration distance of the floated plaque/maximum sagittal length of the plaque) $\times 100(\%)$.

\section{Surgical Procedure}

With the patient in a prone position, we performed a total resection of the posterior vertebral elements at the anterior decompression levels. This maneuver included not only laminectomy but also removal of the transverse processes and pedicles, thus allowed the creation of space bilaterally at the sides of the dural sac for the subsequent anterior decompression. The thoracic nerves at the anterior decompression levels were ligated bilaterally and lifted to improve the viewing of the ossified ligament and the anterolateral aspect of the dural sac. An anterior decompression was then performed posteriorly. Using these surgical maneuvers, the ossification was floated without difficulty (Fig. 4). Removal of beak-type ossification was also achieved using this technique in the earlier 3 patients with exfoliation of adhesions between ossified ligament and the ventral aspect of the dural sac after floating of plaque. ${ }^{4}$ In every step of the anterior decompression, the space created at the bilateral sides of the dural sac and the view created by lifting up of the ligated nerve roots allowed us to see the ossified PLL and the anterolateral aspect of the dural sac directly and easily and use a bur safely (Fig. 4). We placed posterior pedicle screw instrumentation and performed posterolateral fusion using local bone
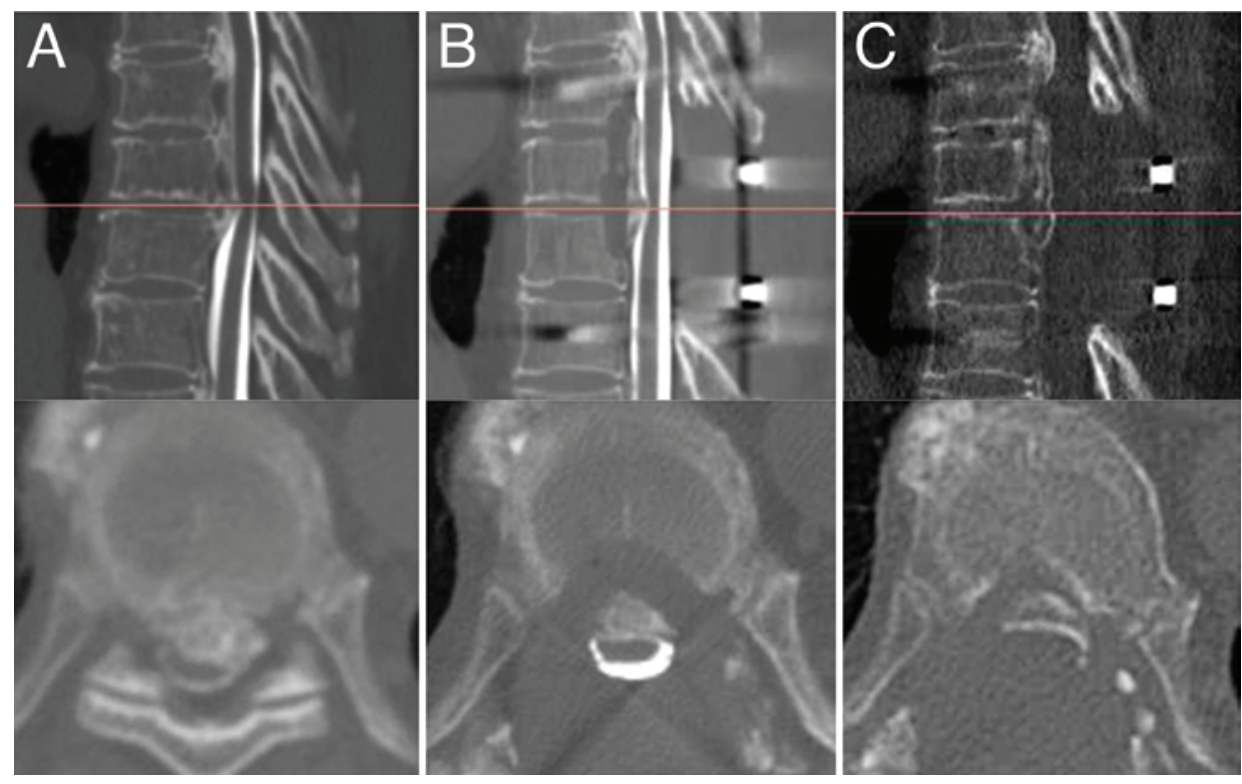

FIG. 1. Case 4. OPLL at T8-9 treated by means of the plaque-floating technique. A and B: Preoperative (A) and 1-month postoperative (B) CT myelograms. C: Postoperative plain CT image obtained 6 months after surgery. Figure is available in color online only. 

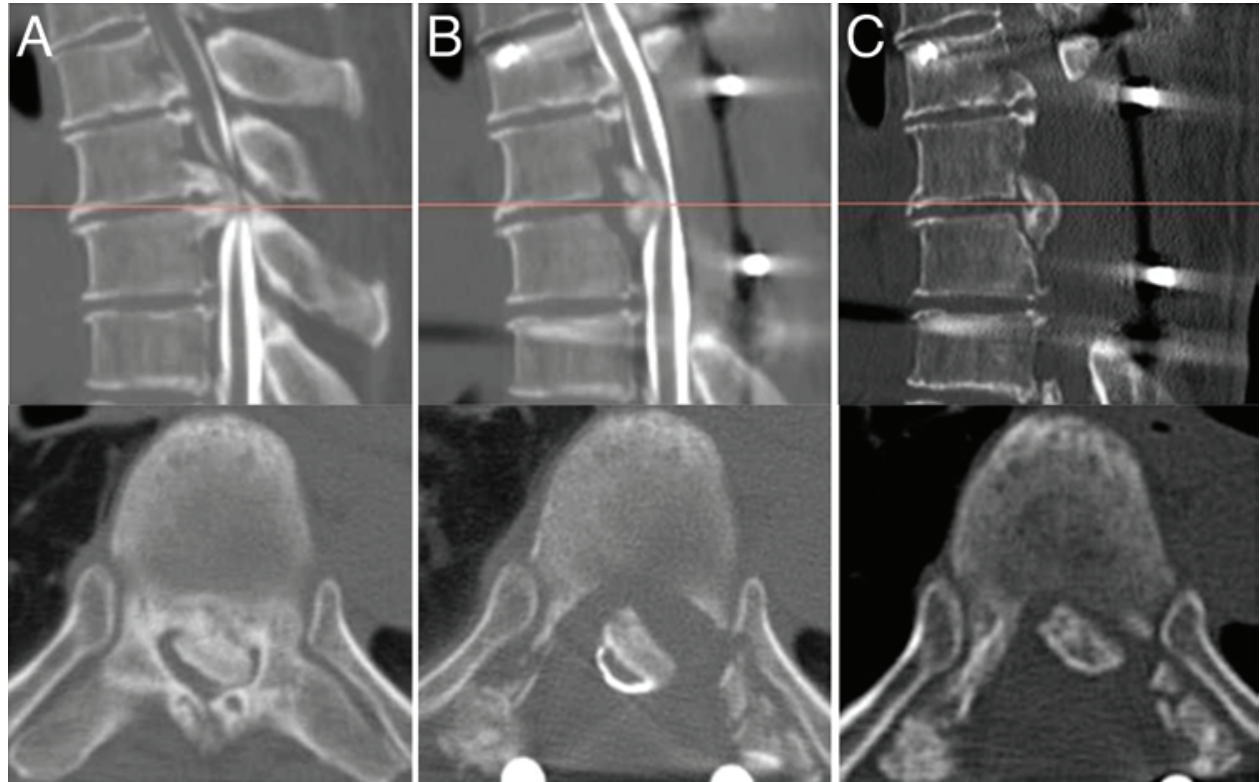

FIG. 2. Case 5. OPLL at T5-6 treated by means of the plaque-floating technique. A and B: Preoperative (A) and 1-month postoperative (B) CT myelograms. C: Postoperative plain CT image obtained 6 months after surgery. Figure is available in color online only.

chips obtained from the resected laminae and transverse processes. In the 3 patients who were treated with plaque floating (that is, those who were treated later in our experience), kyphosis correction with posterior instrumentation was applied after floating because we observed with ultrasonography that the floated plaque was still causing some spinal cord compression. Our technique allows easier kyphosis correction because the thoracic spine at the decompressed levels becomes more flexible after removal of the transverse processes and pedicles than it is when treated via the conventional posterior approach. The advantages and pitfalls of this surgical technique have been described in detail elsewhere. ${ }^{4}$

\section{Results}

\section{Clinical Outcomes}

We used this surgical technique to treat 6 patients with beak-type OPLL in the middle thoracic spine. The complete removal of the ossification at the anterior decompression levels was achieved in 3 patients. Adequate plaque floating was achieved in the other 3 patients. Anterior decompression was performed at 2 consecutive vertebral levels in 5 patients (Cases 1, 2, 3, 5, and 6 in Table 1) and at 3 consecutive vertebral levels in the remaining patient (Case 4). In all 6 patients, 2 pairs of thoracic nerve roots were sacrificed. There was no significant girdle pain requiring medication after surgery. A temporary mild neurological deterioration, evident in muscle weakness of the lower extremities and resolving within 1 month after surgery, and a minor dural tear occurred in 2 of the patients who underwent complete removal of the ossified PLL (Cases 2 and 3 , respectively). No significant complications such as dural tear or neurological deterioration were encountered in the patients who underwent plaque floating. The recovery rates were $52.4 \%$ in the removal group and $60.0 \%$ in the floating group (Table 1).

\section{Outcomes of the Radiographic Parameters}

The mean OPLL occupying ratio in the floating group was $85.3 \%$. In all 3 floating group patients, a minimum concentric bone resection was observed in the posterior portion of the vertebral body, and the floated plaques gradually migrated into the ventral bone resection areas (Figs. 1 and 2). The mean floated plaque migration distances were $2.4 \mathrm{~mm}, 4.3 \mathrm{~mm}, 4.7 \mathrm{~mm}$, and $4.8 \mathrm{~mm}$ at $1,3,6$, and 12 months after surgery. In all 3 patients, bony fusion between the floated plaque and the vertebral body was observed via CT at 12 months after surgery. The mean anterior decompression ratios were $23.5 \%, 42.2 \%, 45.5 \%$, and $46.8 \%$ at $1,3,6$, and 12 months after surgery (Table 2).

\section{Discussion}

The outcomes of surgical treatment of thoracic OPLL compare unfavorably with those of cervical OPLL. ${ }^{6}$ The thoracic spine is naturally kyphotic, and posterior decompression is thus less effective because the backward movement of the spinal cord is restricted. Obviously, anterior spinal cord decompression is ideal for thoracic OPLL if it can be achieved safely and effectively. In all patients in this series, this procedure was used to sufficiently float the plaques of beak-type OPLL without difficulty. A main advantage of this procedure is that it provides more space at the bilateral sides of the dural sac for maneuvering in the anterior decompression relative to the conventional posterior approach. This space in combination with lifting of the ligated thoracic nerves also allows surgeons to directly visualize the OPLL and the anterolateral aspect of the dural sac. In this procedure, surgeons can perform anterior decompression with adequate recognition of the position between the OPLL and the whole dural sac, and this information facilitates the anterior decompression procedure. This advantage is not afforded during anterior decompression via an anterior approach. We therefore 
Occupying ratio $=\mathrm{a} / \mathrm{b} \times 100$

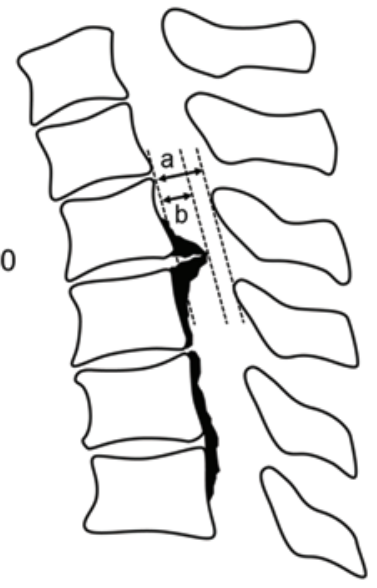

Migration distance of the floated OPLL $=A-B$

Anterior decompression ratio $(\%)=(A-B) / C \times 100$
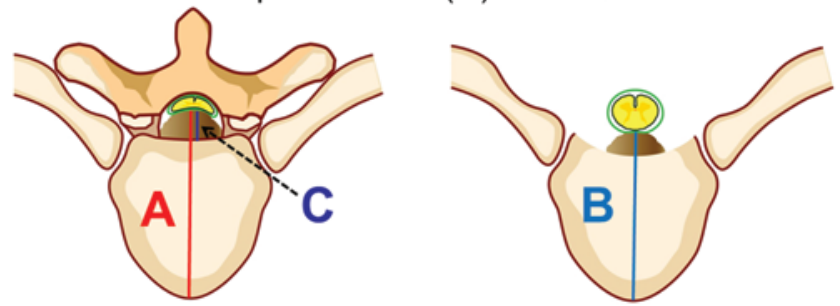

FIG. 3. Radiographic parameters used in this study. Upper: Schematic showing the method of calculating the occupying ratio. The canal diameter (a) is divided by the maximum sagittal length of the ossified PLL (b). Lower: Schematics showing the method of calculating the migration distance of the floated plaque (in millimeters) and the anterior decompression ratio as a percentage $([(A-B) / C] \times 100)$. $A$ is the length from the front edge of a vertebral body to the top of an ossified PLL in a presurgical axial CT image; $B$, the distance from the front edge of a vertebral body to the top of an ossified PLL in a postsurgical axial CT image; and $C$, the length of the ossified PLL. Copyright Satoshi Kato. Published with permission. Figure is available in color online only.

consider that our approach is the safest and most feasible surgical procedure for floating the plaque in patients with beak-type OPLL.

On the other hand, the ossified ligament tends to adhere strongly to the ventral aspect of the dural sac, thus increasing the difficulty of direct removal and the risk of spinal cord injury. Considerable improvements in myelopathy were observed during the postoperative course in all patients who underwent anterior decompression via the procedure described in this study. However, 2 of the 3 patients who underwent removal of the floated plaque experienced significant complications, including a dural tear and temporary neurological deterioration. In this study, the final recovery rate of patients who underwent plaque floating was equivalent to that of patients who underwent plaque removal, and the former had no significant intraoperative or postoperative complications. This result demonstrates that plaque floating via this procedure is sufficiently effective for anterior spinal cord decompression and serves as the most appropriate method without significant risks.

For every case in which the ossification was floated, migration of the floated plaque into the ventral bone resection area was observed during the postoperative period.
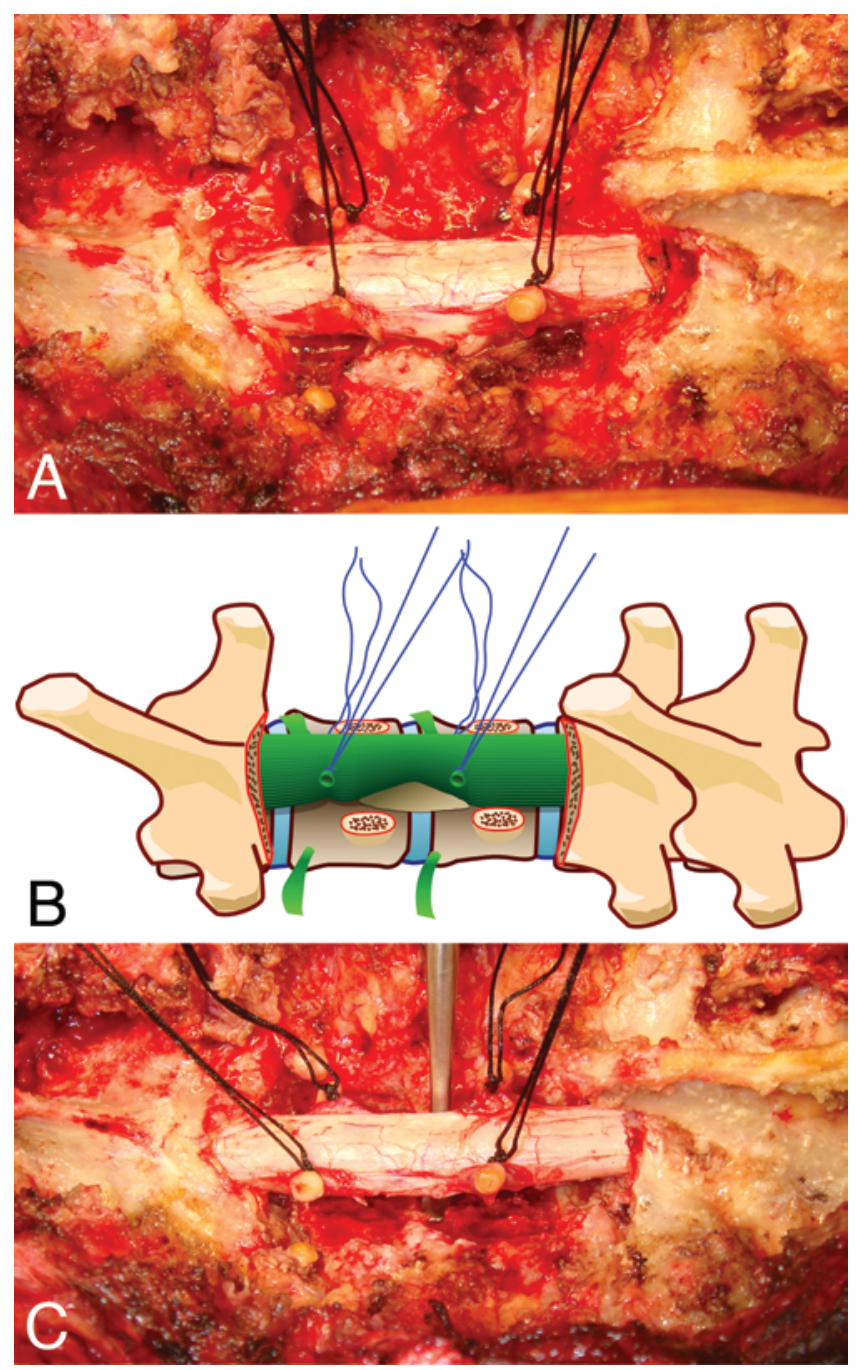

FIG. 4. Case 4. Intraoperative images. A: Photograph taken before anterior decompression. B: Illustration of intraoperative view before anterior decompression. Copyright Satoshi Kato. Published with permission. C: Photograph taken after anterior decompression (floating of ossified PLL). Figure is available in color online only.

This migration had gradually and obviously advanced at 6 months after surgery. Additionally, the majority of the migration had occurred by 3 months after surgery. This is the first report to describe this migration phenomenon in anterior decompression for thoracic OPLL. The CT myelograms obtained 1 month after surgery revealed spinal cord decompression resulting from adequate floating of the ossified PLL (Figs. 2 and 3). The subsequent plaque migration both demonstrated that floating had been completely achieved and provided additional spinal cord decompression during the postoperative course.

\section{Conclusions}

Floating of the ossified PLL via our posterolateral approach-based surgical technique was safe and effective in patients with beak-type OPLL in the thoracic spine. Gradual migration of the floated plaques provided additional spinal cord decompression during the postoperative course. 
TABLE 1. Demographic and clinical characteristics of 6 patients

\begin{tabular}{|c|c|c|c|c|c|c|c|c|c|c|c|c|}
\hline $\begin{array}{l}\text { Case } \\
\text { No. }\end{array}$ & $\begin{array}{l}\text { Age } \\
\text { (yrs) }\end{array}$ & Sex & $\begin{array}{c}\text { Anterior } \\
\text { Decompression } \\
\text { Levels }\end{array}$ & $\begin{array}{l}\text { Instrumented } \\
\text { Fusion Levels }\end{array}$ & $\begin{array}{c}\text { Anterior } \\
\text { Decompression } \\
\text { Type }\end{array}$ & $\begin{array}{l}\text { OR } \\
(\%)\end{array}$ & $\begin{array}{l}\text { Duration of } \\
\text { Follow-Up }\end{array}$ & History & $\begin{array}{c}\text { Operative } \\
\text { Complication }\end{array}$ & $\begin{array}{l}\text { Preop } \\
\text { JOA }\end{array}$ & $\begin{array}{l}\text { Postop } \\
\text { JOA }\end{array}$ & $\begin{array}{c}\text { Recovery } \\
(\%)\end{array}$ \\
\hline 1 & 63 & M & T6-7 & T4-9 & Removal & 71 & 34 & $\mathrm{RF}, \mathrm{HT}$ & None & 1 & 5 & $57^{*}$ \\
\hline 2 & 65 & $\mathrm{~F}$ & T5-6 & T3-8 & Removal & 51 & 27 & DM, HT & Dural tear & 8 & 9.5 & 50 \\
\hline 3 & 62 & M & T5-6 & T3-8 & Removal & 67 & 23 & DM, HT & Neurol deter & 5 & 8 & 50 \\
\hline 4 & 53 & $\mathrm{~F}$ & T7-9 & T5-11 & Floating & 82 & 23 & DM & None & 4.5 & 8 & 54 \\
\hline 5 & 51 & $\mathrm{~F}$ & T5-6 & T3-8 & Floating & 93 & 19 & CP, LC & None & 1.5 & 6 & $69 \dagger$ \\
\hline 6 & 58 & $F$ & T3-4 & T1-7 & Floating & 81 & 14 & DM & None & 0.5 & 6.5 & 57 \\
\hline
\end{tabular}

$\mathrm{CP}=$ cerebral palsy; $\mathrm{DM}=$ diabetes mellitus; $\mathrm{HT}$ = hypertension; JOA = JOA score; $\mathrm{LC}=$ liver cirrhosis; neurol deter = neurological deterioration; OR = occupying ratio; $\mathrm{RF}=$ renal failure.

* In Case 1, the total JOA score was calculated as 8 points by eliminating the score of 3 points for bladder function due to the patient's anuric renal failure.

$\dagger$ In Case 5, the total JOA score was calculated as 8 points by eliminating the score of 3 points for lower-extremity motor function due to the patient's cerebral palsy.

TABLE 2. Radiographic data for patients treated with the plaque-floating technique

\begin{tabular}{lrrrr}
\hline & \multicolumn{5}{c}{ Time Since Op in Mos } \\
\cline { 2 - 5 } Variable \& Case No. & 1 & 3 & 6 & 12 \\
\hline Migration distance of floated OPLL $(\mathrm{mm})$ & & & & \\
\hline 4 & 2.9 & 5.0 & 5.3 & 5.4 \\
\hline 5 & 1.5 & 4.0 & 4.3 & 4.4 \\
\hline 6 & 2.8 & 4.0 & 4.4 & 4.6 \\
\hline Anterior decompression rate (\%) & & & & \\
\hline 4 & 31.9 & 54.9 & 58.2 & 59.3 \\
\hline 5 & 13.6 & 36.0 & 39.1 & 40.0 \\
\hline 6 & 25.0 & 35.7 & 39.3 & 41.1 \\
\hline Percentage recovery rate in JOA score (\%) & & & & \\
\hline 4 & 31 & 46 & 54 & 54 \\
\hline 5 & 23 & 54 & 69 & 69 \\
\hline 6 & 43 & 52 & 57 & 57 \\
\hline
\end{tabular}

\section{References}

1. Fujimura Y, Nishi Y, Nakamura M, Toyama Y, Suzuki N: Long-term follow-up study of anterior decompression and fusion for thoracic myelopathy resulting from ossification of the posterior longitudinal ligament. Spine (Phila Pa 1976) 22:305-311, 1997

2. Hirabayashi K, Miyakawa J, Satomi K, Maruyama T, Wakano K: Operative results and postoperative progression of ossification among patients with ossification of cervical posterior longitudinal ligament. Spine (Phila Pa 1976) 6:354-364, 1981

3. Ido K, Shimizu K, Nakayama Y, Yamamuro T, Shikata J, Matsushita M, et al: Anterior decompression and fusion for ossification of posterior longitudinal ligament in the thoracic spine. J Spinal Disord 8:317-323, 1995

4. Kato S, Murakami H, Demura S, Yoshioka K, Hayashi H, Tsuchiya H: Novel surgical technique for ossification of posterior longitudinal ligament in the thoracic spine. J Neurosurg Spine 17:525-529, 2012

5. Kurosa Y, Yamaura I, Nakai O, Shinomiya K: Selecting a surgical method for thoracic myelopathy caused by ossification of the posterior longitudinal ligament. Spine (Phila Pa 1976) 21:1458-1466, 1996

6. Matsumoto M, Chiba K, Toyama Y, Takeshita K, Seichi A, Nakamura K, et al: Surgical results and related factors for ossification of posterior longitudinal ligament of the thoracic spine: a multi-institutional retrospective study. Spine (Phila Pa 1976) 33:1034-1041, 2008

7. Matsuyama Y, Yoshihara H, Tsuji T, Sakai Y, Yukawa Y, Nakamura H, et al: Surgical outcome of ossification of the posterior longitudinal ligament (OPLL) of the thoracic spine: implication of the type of ossification and surgical options. J Spinal Disord Tech 18:492-498, 2005

8. Min JH, Jang JS, Lee SH: Clinical results of ossification of the posterior longitudinal ligament (OPLL) of the thoracic spine treated by anterior decompression. J Spinal Disord Tech 21:116-119, 2008

9. Takahata M, Ito M, Abumi K, Kotani Y, Sudo H, Minami A: Clinical results and complications of circumferential spinal cord decompression through a single posterior approach for thoracic myelopathy caused by ossification of posterior longitudinal ligament. Spine (Phila Pa 1976) 33:1199-1208, 2008

10. Tokuhashi Y, Matsuzaki H, Oda H, Uei H: Effectiveness of posterior decompression for patients with ossification of the posterior longitudinal ligament in the thoracic spine: usefulness of the ossification-kyphosis angle on MRI. Spine (Phila Pa 1976) 31:E26-E30, 2006

11. Tomita K, Kawahara N, Baba H, Kikuchi Y, Nishimura H: Circumspinal decompression for thoracic myelopathy due to combined ossification of the posterior longitudinal ligament and ligamentum flavum. Spine (Phila Pa 1976) 15:11141120,1990

12. Tsuzuki N, Hirabayashi S, Abe R, Saiki K: Staged spinal cord decompression through posterior approach for thoracic myelopathy caused by ossification of posterior longitudinal ligament. Spine (Phila Pa 1976) 14:1623-1630, 2001

13. Yonenobu K, Korkusuz F, Hosono N, Ebara S, Ono K: Lateral rhachotomy for thoracic spinal lesions. Spine (Phila Pa 1976) 15:1121-1125, 1990

\section{Author Contributions}

Conception and design: Kato, Murakami. Acquisition of data: Kato, Hayashi, Yokogawa, Fang. Analysis and interpretation of data: Kato, Demura, Yoshioka, Hayashi, Yokogawa. Drafting the article: Kato. Critically revising the article: Murakami, Demura, Yoshioka, Fang, Tsuchiya. Administrative/technical/material support: Murakami, Tsuchiya. Study supervision: Murakami, Tsuchiya.

\section{Correspondence}

Satoshi Kato, Department of Orthopaedic Surgery, Kanazawa University School of Medicine, 13-1 Takara-machi, Kanazawa, 920-8641, Japan.email: skato323@gmail.com. 